\title{
Temperature and territoriality in the Duke of Burgundy butterfly, Hamearis lucina
}

\author{
M. P. Hayes ${ }^{1}$ (D) - G. E. Hitchcock ${ }^{2}$ 'R. I. Knock ${ }^{2}$ - C. B. H. Lucas ${ }^{1}$ - E. C. Turner ${ }^{1}$
}

Received: 19 December 2018 / Accepted: 21 June 2019 / Published online: 4 July 2019

(c) The Author(s) 2019

\begin{abstract}
The Duke of Burgundy butterfly (Hamearis lucina) has undergone severe declines over the last four decades. However, in recent years the UK population appears to have begun expanding again. This is likely to be due to beneficial management, although a warming regional climate may also have contributed to the resurgence of this spring-flying species. In this study, we investigated the effect of air temperature on the flight behaviour of adult male Duke of Burgundy butterflies. We also looked at the ability of adult males to behaviourally thermoregulate their body temperature and assessed their tendency to remain within small established territories. Increasing air temperature lead to a marked increase in the number and duration of flights associated with territorial behaviour but had no significant effect on other flights. This suggests that high temperatures are particularly important for sustaining energetically-demanding flights involved in territory defence and mate interception, which could impact the reproductive potential of Duke of Burgundy populations. We also found that butterflies had only a limited ability to regulate their body temperature behaviourally and may, therefore, be especially dependent on suitable environmental conditions to maintain the right temperatures for these flights. During observations, most males also remained confined to a few square meters within their territories, which could further restrict butterfly ability to thermoregulate by limiting relocation to other habitat types. However, we did find more males to leave the confines of their territories than expected from reports in previous studies. Our findings highlight the key role that warm, sheltered locations on reserves have in supporting the Duke of Burgundy. If this traditionally poor disperser is to take advantage of a warmer climate and extend its range North, a close network of such areas, appropriately managed, may be critical.
\end{abstract}

Keywords Butterfly $\cdot$ Calcareous grassland $\cdot$ Climate change $\cdot$ Duke of Burgundy $\cdot$ Habitat management $\cdot$ Hamearis lucina $\cdot$ Territoriality $\cdot$ Thermoregulation

\section{Introduction}

In the UK, $76 \%$ of butterfly species have experienced longterm declines, extending back to at least the mid-1970s, and many species currently occupy only a small fraction of their historical range. However, when data from the last decade is considered alone, the outlook for butterflies in the UK does not seem so bleak (Fox et al. 2015). From 2005 to 2014 some threatened butterfly species appear to have halted

\section{P. Hayes}

mph51@cam.ac.uk

1 Department of Zoology, University Museum of Zoology, Downing Street, Cambridge CB2 3EJ, UK

2 Wildlife Trust for Bedfordshire, Cambridgeshire and Northamptonshire, Unit 2, St Johns Barn, Griffin Farm, Conger Lane, Toddington, Bedfordshire LU5 6BT, UK their rapid declines or to have even begun reversing them, with modest increases in distribution or abundance reported across the country (Fox et al. 2015). Although these recent upturns are dwarfed by the long-term declines and species have a long way to go before reaching the extent of their former ranges, such positive changes may give reason for cautious optimism into the future. However, for conservationists to take advantage of these increases, it is important to understand their underlying causes. Alongside improved conservation management, a warming regional climate has been implicated as a possible contributing factor (Parmesan et al. 1999; Fox et al. 2015).

The Duke of Burgundy butterfly (Hamearis lucina L. 1758 ) is one species that has undergone a recent upturn nationally. It has experienced extreme long-term decline, losing $84 \%$ of its 1974 distribution and $42 \%$ of its abundance. However, since 2005 the UK population has undergone a 
small range expansion and grown in abundance by $67 \%$ (Fox et al. 2015). The species has also shifted northwards in its European range and begun to emerge earlier in the UK during the past few decades, suggesting that rising temperatures may have played a role (Parmesan et al. 1999; Oates 2000; Fartmann 2006). The adult life stage of the Duke of Burgundy has been little studied, with few papers investigating its ecology and habitat requirements in the UK (Turner et al. 2009; Hayes et al. 2018). However, what evidence is available suggests that high temperatures are important for adults. Turner et al. (2009) found adults to favour warm, sheltered locations and males of the species are known to defend small, sunny territorial patches, no more than a few metres in diameter, from which they rarely move (Kirtley 1995; Bourn and Warren 1998). Favourable sites can be returned to year on year, with many males perching within a few metres of one another. In these locations individual territories become harder to separate and leks can form (Kirtley 1995; Oates 2000). These findings are supported by distribution data from Hayes et al. (2018), which found adult males to be highly constrained in their small-scale range within a habitat and occupying only the most sheltered parts of the environment. Given the Duke of Burgundy's preference for a warm environment, further temperature increases of $1-4{ }^{\circ} \mathrm{C}$, predicted in the UK by the end of the century (Intergovernmental Panel on Climate Change 2014), may continue to benefit local populations (Parmesan et al. 1999; Fox et al. 2015). However, in order to better understand the potential long-term impacts of a changing climate on the Duke of Burgundy and to tailor effective habitat management, it is important to understand why warmer areas are selected by this butterfly.

Turner et al. (2009) suggest that the butterfly's preference for warm, sheltered locations may be due to these areas promoting flight and sexual activity in sub-optimal weather conditions. This could be especially important for the Duke of Burgundy, which, as a spring-flying butterfly, is active at a relatively cool time of the year (Wickman 1985). Ectothermic organisms rely on their environment for temperature regulation, enabling them to raise their body temperature and increase the rate of metabolic activity (Huey and Kingsolver 1989). For small ectotherms such as insects, which have large surface area to volume ratios and negligible ability to retain heat (Stevenson 1985), this means that activity levels are largely dependent on the temperature of their microclimate. Therefore, energetically demanding feats, such as active flight, territory defence and mating behaviour usually require high ambient temperatures (Wasserthal 1975; Larsson and Tengo 1989; Larsson and Kustvall 1990; Ide 2010; Bennett et al. 2014). For example, Tsubaki and Samejima (2016) found male Mnais costalis damselflies to have higher reproductive outputs when occupying territories that were exposed to the sun for longer periods of time. They suggest this could be due to males being able to attain higher thoracic temperatures, allowing more regular and intense courtship behaviour. Similarly, in many butterfly species, increasing air temperature can cause a switch in male mate location strategy, from a passive perching and intercept behaviour to that of actively flying and patrolling for females (Scott 1974; Shreeve 1984; Wickman 1985; Van Dyck and Matthysen 1998; Merckx and Van Dyck 2005; Ide 2010). Patrolling males interact with more females than perched individuals, meaning they can increase their relative mating frequency and potentially their reproductive output (Shreeve 1984). The Duke of Burgundy has not been observed to exhibit different mate location strategies, with all males perching in a territory and intercepting passing females (Kirtley 1995; Oates 2000; Turner et al. 2009; Hayes et al. 2018). However, by influencing activity levels and behavioural frequency, especially of energetic flights related to territory defence and intercepting females, temperature could still have a large impact on the reproductive success and fitness of individuals (Huey and Kingsolver 1989; Willmer 1991; Berwaerts and Van Dyck 2004).

Here, we investigate the effects of air temperature, butterfly density and wind speed on the flight behaviour of adult male Duke of Burgundy butterflies. We also investigate the ability of the butterfly to buffer its thoracic temperature compared to ambient conditions, and how frequently individuals are observed to leave their territories. With this information we aim to determine: (1) whether higher air temperatures are associated with increased flight activity in male Duke of Burgundy butterflies and if this is specifically linked to an increase in energetically demanding flights, such as those involved in territory defence and courtship; (2) if males can significantly alter their body temperature away from that of their surrounding environment, or if they are instead reliant on the presence of a suitably warm microclimate (3) what percentage of males remain on their territory throughout observations and are therefore limited in their ability to buffer their short-term temperature by moving to other microhabitats.

As a result of this work, we aim to improve knowledge of the environmental features that promote active flights in the Duke of Burgundy butterfly and inform adaptable management regimes that will remain suitable under shifting climates.

\section{Methods}

\section{Study site and Duke of Burgundy population}

All fieldwork was carried out at Totternhoe Quarry, Bedfordshire, an unimproved chalk grassland reserve owned and managed by the Bedfordshire, Cambridgeshire and 
Northamptonshire (BCN) Wildlife Trust (BCN Wildlife Trust and Totternhoe 2017). At 13.6 hectares, the site is quite small, but it hosts a relatively large population of Duke of Burgundy butterflies for its size. For more information on the site and study population see Hayes et al. (2018).

The Duke of Burgundy is a relatively small butterfly, with an adult wingspan of approximately $30 \mathrm{~mm}$ (Butterfly Conservation 2019). The species is an early flier and in the UK is on the wing from mid -April until the end of June (Oates 2000). It is found in two main habitat types: sheltered coppiced woodland clearings and scrubby calcareous grassland (Ellis et al. 2011). However, a reduction in suitable woodland habitats means that the vast majority of populations in the country are now found on grassland sites (Emmet and Heath 1989; Sparks et al. 1994; Oates 2000). Eggs are laid on plants of the genus Primula (Oates 2000), with females usually selecting larger, partially shaded Cowslips, Primula veris, or Primroses, Primula vulgaris, for oviposition (Fartmann 2006). For full details on the ecology and lifecycle of the Duke of Burgundy please see Turner et al. (2009) and Hayes et al. (2018).

\section{Recording flight activity levels of adult males}

In 2008, 2009, and 2017, Totternhoe Quarry Reserve was surveyed between April and June for adult Duke of Burgundy butterflies. In 2008, only areas of the site known to commonly host large numbers of male Duke of Burgundy (holding territories) were visited, whereas in 2009 and 2017, the entire reserve was searched, with the exception of areas of dense scrub. Surveys of the whole reserve involved teams of researchers systematically searching the entire site each day, walking back and forth making repeat passes, ensuring that no areas were more than $20 \mathrm{~m}$ from a surveyor on any visit. A recent GPS map of the reserve (please see Hayes et al. 2018) was used to guide surveys and ensure that all areas, even difficult to reach patches isolated by dense scrub, were searched. Other measures implemented to avoid bias included changing the starting point and direction walked across the reserve on each visit. This prevented the same areas of the site being reached at the same time each day, which would impact the local temperature levels recorded. Whenever a male Duke of Burgundy butterfly was seen, its flight activity levels were immediately recorded during a short observation period. Surveying then continued until the next male was found and the process was repeated.

In 2008, distinct types of flight behaviour exhibited by adult Duke of Burgundy were determined and individual butterflies were observed for as long as possible, in order to gauge a feasible time span for analysing Duke of Burgundy behaviour. As 33\% of butterflies left the observation area within half an hour, a short observation period was decided upon, with the initial 10 min of observations in 2008 being used for analyses. In subsequent years, whenever a Duke of Burgundy butterfly was observed, its sex was noted and we then attempted to view the individual, uninterrupted for a full $10 \mathrm{~min}$. Different types of flight behaviour determined were categorised as non-territorial and territorial flights. Non-territorial flights consisted of unidirectional changes in perch location, whereas territorial flights included circular territory perimeter checks (flying around the perch area for a few seconds before returning to a similar or the same location), intercept flights (chasing other flying insects entering a territory, including passing females) and escalating spiral flights (where Duke of Burgundy males spiralled into the air with each other). Over the 10 min observation period, the number and duration of all territorial and non-territorial flights (summed time between taking off and landing for each activity) were recorded. In addition, we noted whether a male flew away from its territory without pursuing a female before $10 \mathrm{~min}$ had expired and calculated the percentage of males undertaking this behaviour. Where possible, males were followed and their activity after leaving a territory was recorded.

\section{Measuring temperature and other variables}

Temperature during the observation periods was recorded in three different ways. Firstly, for all 3 years of study, at the end of the $10 \mathrm{~min}$ air temperature in the immediate vicinity of the observed individual was recorded in the shade using a sensitive temperature probe (TECPEL Digital Thermometre 305B). Secondly, in 2009 and 2017, at the start of the $10 \mathrm{~min}$ a dead butterfly on a stick, with its wings spread as if in a basking position, was placed in the same area as the butterfly being observed. At the end of the observation period, we recorded the dead butterfly's temperature by touching the same temperature probe onto its thorax. Initially, a dead Duke of Burgundy butterfly was used. However, this specimen became damaged during fieldwork and so a Ringlet butterfly (with similar colouring and wings cut to the size of a Duke of Burgundy) was used instead. Finally, in 2009, after observations were completed, the observed living Duke of Burgundy butterflies were caught using a butterfly net and their temperature recorded by immediately touching the probe gently onto their thorax. Butterflies were then released without delay, with no individuals showing any damage. In addition to temperature, the number of males at each location at the time of observation was recorded for all 3 years of observations. Males were determined as coming from the same location (belonging to the same territorial lek) when their circular territorial perimeter check flights overlapped. For 2017 only, wind speed was also measured at the end of the observation period, using a Proster TL017 Handheld Anemometer. 


\section{Analysis}

We used R version 3.4.3, running the packages 'stats', 'boot', 'MASS', 'pscl' and 'car', for all analyses, with all data from 2008, 2009 and 2017 being included.

As each observation period recorded both territorial and non- territorial flights, comparing data on both flight types together would incorrectly assume independence (for each individual, time spent undertaking territorial flights reduces the time available to undertake non-territorial flights and vice versa). Therefore, flight types were analysed separately, unless analysing relative proportions. To investigate the effect of male density on territorial and non-territorial flights and how this interacts with temperature change, Wilcoxon Signed-Rank Tests were used to compare the mean number of territorial and non-territorial flights undertaken by solitary individuals and individuals on territories with multiple males, during the 10 min observation periods. The mean amount of time spent undertaking the two types of flight by solitary and grouped individuals was also compared. When there was evidence of a significant difference, data were fitted to negative binomial distributions and generalised linear regressions were performed to investigate changes in the number (Number of flights $=$ Air Temperature $\times$ Grouped/Solitary males) and duration of flights (Duration of flights $=$ Air Temperature $\times$ Grouped/Solitary males).

Having accounted for the effect of male density on male Duke of Burgundy flight behaviour, the next stage investigated the effect of air temperature in isolation. All observations where more than one male was present on a lek were excluded from this analysis, to remove this confounding factor, resulting in 29 of 95 total observations being removed. In order to account for the large number of butterflies that did not fly and gave 0 values, two logistic generalised linear regressions were used to assess whether the occurrence of territorial or non-territorial behaviour increased with temperature (Presence of flight behaviour $=$ Air temperature). After removing observations of 0 , negative binomial distributions were fitted to the remaining data set and four generalized linear regressions were performed, investigating whether the number (Number of flights $=$ Air temperature) and duration (Duration of flights $=$ Air temperature) of territorial and non-territorial flights changed with air temperature. Finally, two binomial generalized linear regressions were used to investigate the proportional change in territorial activity versus non-territorial activity with increasing air temperature (Proportion of territorial flights $=$ Air temperature). For these analyses, the number of territorial flights and the time spent performing territorial flights were compared to the total number and duration of all flights performed during the $10 \mathrm{~min}$ observation periods. Proportions were also weighted according to the total number and duration of all flights performed during each observation period. Where data points had high leverage on models (Heiberger and Holland 2004), they were removed and models were re-run to assess whether the same statistical outcome was reached. In all cases the same outcome was reached, so outlying high leverage points were retained and these results only are presented here.

To compare the different methods of recording temperature, a multiple regression was used to compare air temperature to that of both living butterflies from 2009 and dead butterflies observed in 2009 and 2017 (Butterfly Temperature $=$ Air Temperature $\times$ Alive/Dead).

\section{Results}

Across the 3 years of study, 160 adult Duke of Burgundy butterflies were located for behavioural observations. 118 males and 25 females were observed, with the remaining 17 individuals flying away before they could be sexed, usually due to disturbance from an observer. Two adult pairs were observed mating for the full observation period, approximately two metres up in hawthorn scrub, Crataegus monogyna. Of the remaining 116 non-mating Duke of Burgundy males, 95 were observed for a full $10 \mathrm{~min}$ and were used for further analyses. Twenty-nine of these individuals contested territories with other males. Sixteen males performed no flight activities at all, whilst 63 performed at least one territorial flight and 56 performed at least one non-territorial flight. Air temperatures recorded at the end of observation periods ranged from 12.5 to $28.5^{\circ} \mathrm{C}$ with a mean of $18.5^{\circ} \mathrm{C}$ $(\mathrm{SE}=0.37)$. Wind speed for all observations were uniformly very low, with only three recordings exceeding three metres per second, which is equivalent to a light breeze on the Beaufort Scale (Met Office 2017). As wind speed remained largely constant across all observations it was not used in further analysis.

\section{Temperature and male density}

The number of males on a lek had a significant effect on the number (Wilcoxon Signed-Rank Test, $n=95, W=1410.5$, $p<0.001$ ) and total duration (Wilcoxon Signed-Rank Test, $n=95, W=1417.5, p<0.001)$ of territorial flights undertaken by Duke of Burgundy butterflies. The mean number of territorial flights during observation periods were 2.30 $(\mathrm{SE}=0.43)$ and $4.44(\mathrm{SE}=0.58)$, for isolated and grouped males respectively, with the mean total duration of flights being $21.6(\mathrm{SE}=3.83)$ and $46.3(\mathrm{SE}=6.89)$ seconds. However, there was no difference in the number of non-territorial flights (Wilcoxon Signed-Rank Test, $n=95, W=1115.5$, $p=0.161$ ) or the amount of time spent performing nonterritorial flights (Wilcoxon Signed-Rank Test, $n=95$, $W=1085.5, p=0.260)$. The mean number of flights were 
$1.18(\mathrm{SE}=0.31)$ and $1.14(\mathrm{SE}=0.27)$, with mean total durations of $9.08(\mathrm{SE}=2.35)$ and $11.7(\mathrm{SE}=4.53)$ seconds, for isolated and grouped males respectively. Further investigation of the significant difference in territorial flight behaviour showed evidence for a significant interaction and a joint effect with air temperature on the number (Generalized negative binomial regression, $n=95, z_{3,91}=3.498, p<0.001$ ) and duration (Generalized negative binomial regression, $n=95, z_{3,91}=3.045, p=0.002$ ) of territorial flights performed by male Duke of Burgundy butterflies. At lower temperatures, the number of territorial behaviours is much higher when multiple males are present (Fig. 1). However, for males occupying territories by themselves, an increase in air temperature resulted in a rapid rise in the frequency and duration of territorial behaviour, with males occupying territories with multiple males showing a much less marked increase (Fig. 1).

\section{Temperature and type of flight}

The presence of territorial flights increased with air temperature (Generalized logistic regression, $n=66, z_{1,64}=3.357$, $p<0.001$ ), with $80 \%$ of individuals expected to perform at least one territorial flight above $21.5^{\circ} \mathrm{C}$. However, the occurrence of non-territorial flights was unaffected by temperature (Generalized logistic regression, $n=66, z_{1,64}=0.287$, $p=0.774$; Fig. 2).

When considering just the males that showed flight behaviour, air temperature again showed different effects on each type of flight. For territorial behaviour, flight number (Generalized negative binomial regression, $n=34$, $z_{1,32}=2.641, p=0.00826$ ) and duration (Generalized negative binomial regression, $n=34, z_{1,32}=3.583, p<0.001$ ) increased with air temperature, while number (Generalized negative binomial regression, $n=27, z_{1,25}=-0.677$, $p=0.499$ ) and duration (Generalized negative binomial regression, $n=27, z_{1,25}=-0.215, p=0.830$ ) of non-territorial flights was not altered (Fig. 3). This resulted in the proportion of territorial flights (Generalized binomial regression, $\left.n=50, z_{1,48}=5.673, p<0.001\right)$ and proportion of time spent undertaking territorial flights (Generalized binomial regression, $\left.n=50, z_{1,48}=15.620, p<0.001\right)$ increasing relative to non-territorial flights as temperatures increased (Fig. 4). $80 \%$ of all flight behaviour was territorial above an air temperature of $19.6^{\circ} \mathrm{C}$.

\section{Butterfly body temperature and territory occupation}

There was no evidence of a significant interaction between air temperature and whether a butterfly was alive or dead on body temperature (Multiple regression $n=96$, $\left.t_{3,92}=-0.757, p=0.451\right)$, so the interaction term was removed and parallel regressions were fitted, indicating that living butterflies responded to temperature increases in the same way as dead butterflies (Fig. 5). The body temperature of passive, dead and active, living butterflies increased significantly with ambient air temperature (Multiple regression $n=96, t_{2,93}=17.4, p<0.001$ ), with thoracic temperature increasing by $1.3{ }^{\circ} \mathrm{C}\left(\mathrm{SE}=0.07^{\circ} \mathrm{C}\right)$, on

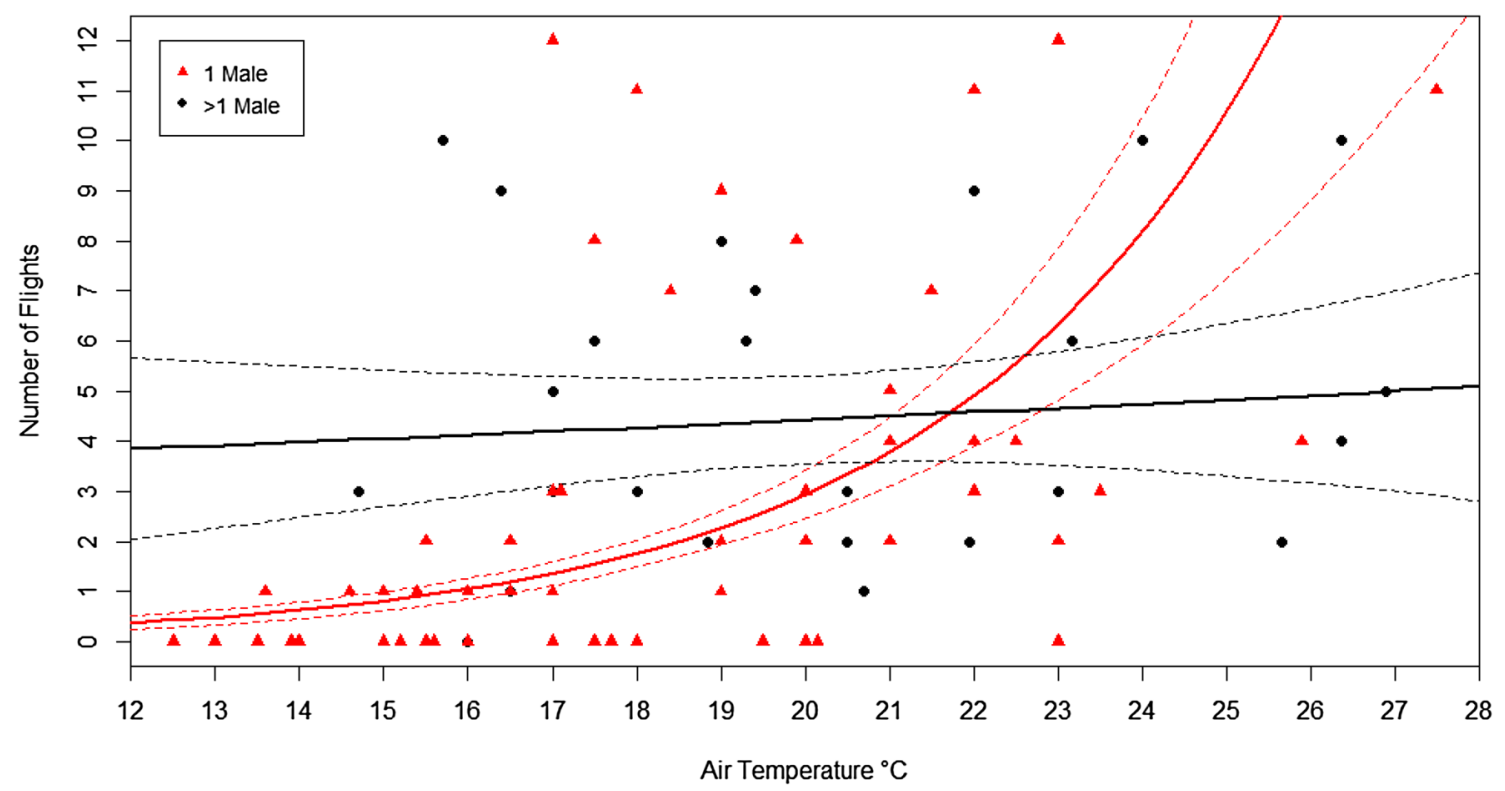

Fig. 1 Number of territorial flights performed by solitary male Duke of Burgundy butterflies or individuals with at least one other male present, plotted against air temperature, during 10 min observation periods. Generalized regression lines are plotted ( \pm one standard error) 

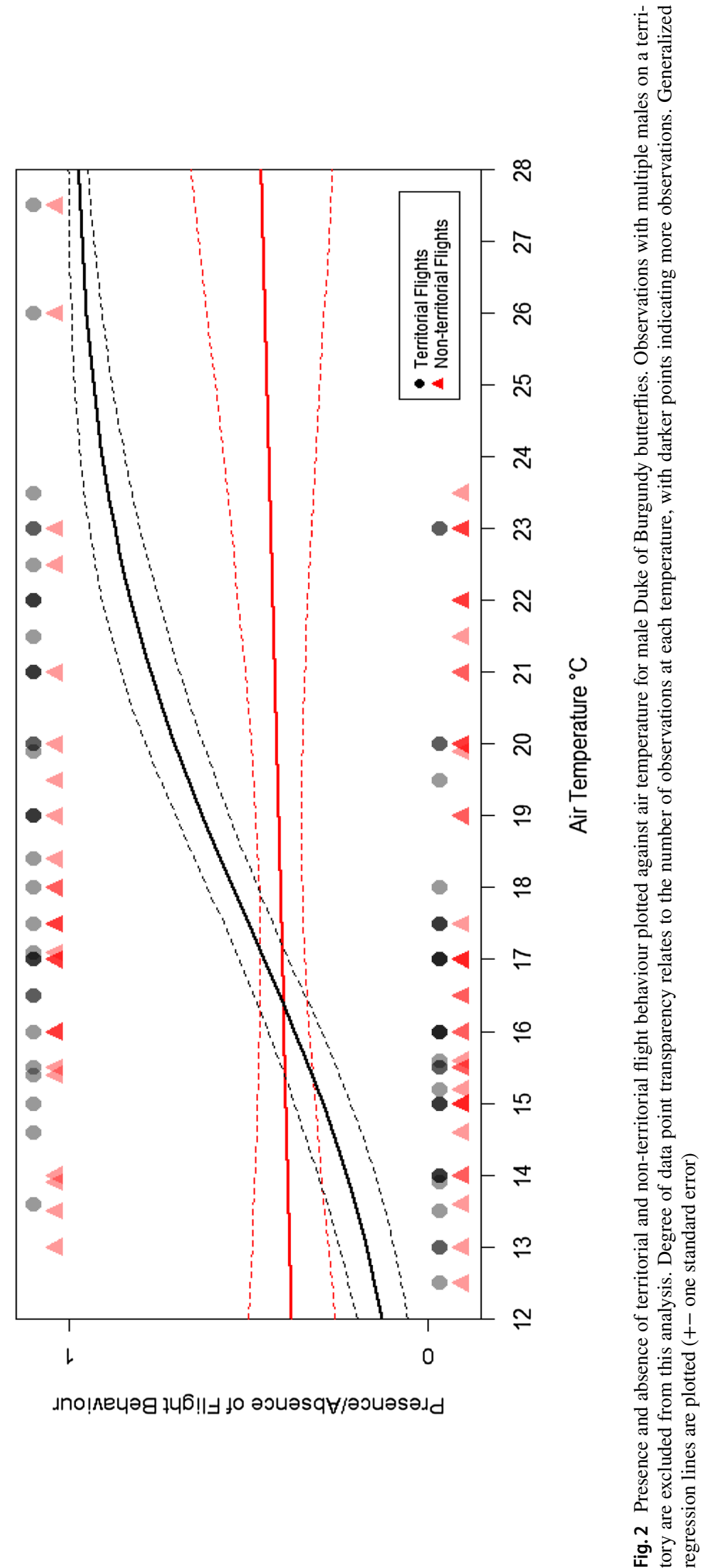


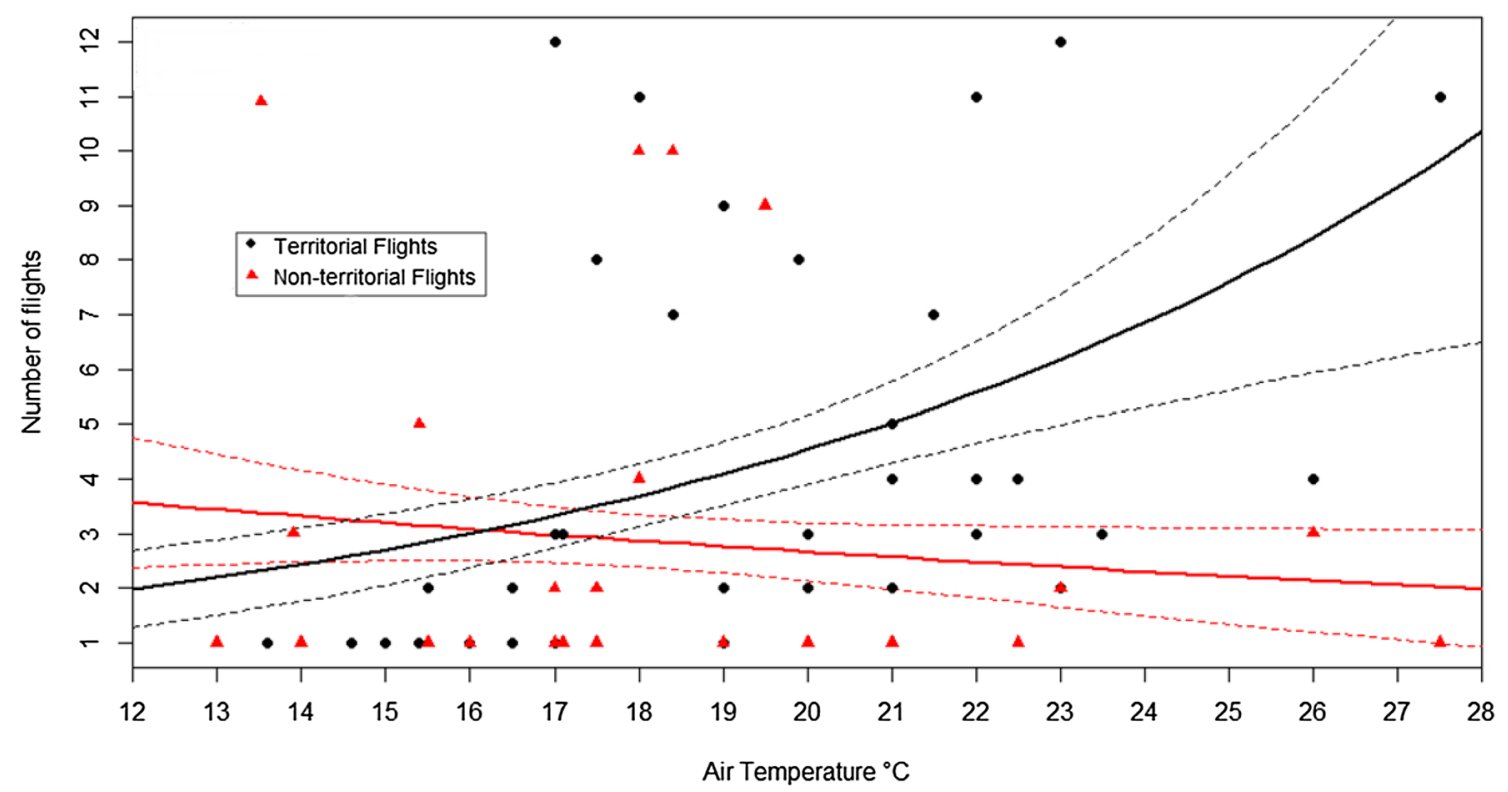

Fig. 3 Number of territorial and non-territorial flights performed during 10 min observation periods plotted against air temperature for male Duke of Burgundy butterflies. Observations with multiple males on a territory and individuals that did not fly during the observation period are excluded from this analysis. Generalized regression lines are plotted ( \pm one standard error)

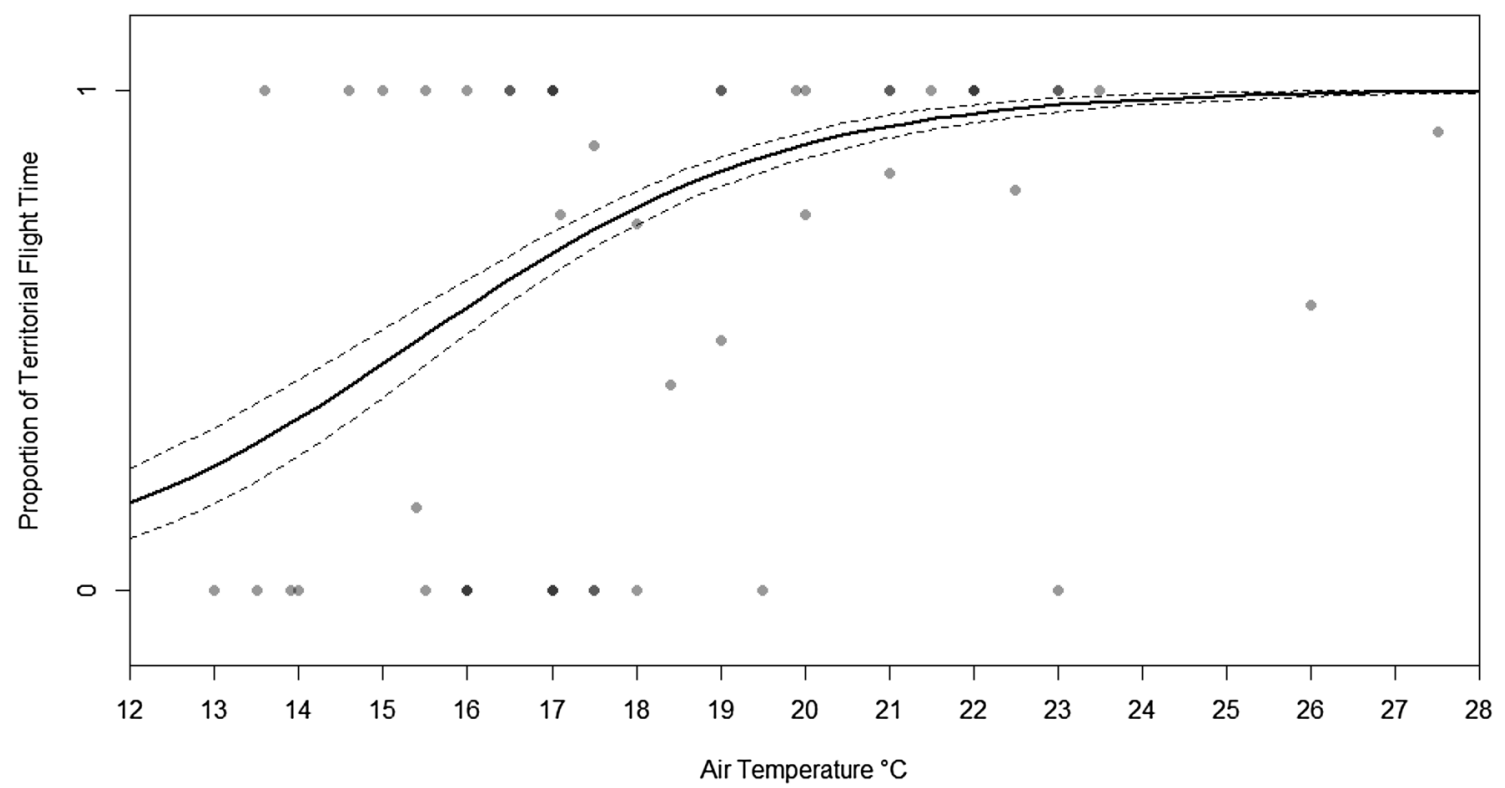

Fig. 4 Proportion of time spent undertaking territorial flights, out of all flights performed during $10 \mathrm{~min}$ observation periods, plotted against air temperature for male Duke of Burgundy butterflies. Degree of data point transparency relates to the number of observations at each temperature, with darker points indicating more observa-

average, with every $1{ }^{\circ} \mathrm{C}$ rise in air temperature (Fig. 5). However, living Duke of Burgundy butterflies were on average $3.0{ }^{\circ} \mathrm{C}\left(\mathrm{SE}=0.53{ }^{\circ} \mathrm{C}\right)$ warmer than dead specimens (Multiple regression $n=96, t_{2,93}=-5.6, p=<0.001$ ) (Fig. 5). tions. Observations with multiple males on a territory and individuals that did not fly during the observation period are excluded from this analysis. Generalized regression lines are plotted ( \pm one standard error)

Twenty-one of the 116 non-mating males flew away from their territories, without following a conspecific, before $10 \mathrm{~min}$ expired. The majority of these males flew further than could be followed, but one adult male from 2008 and two from 2017 were tracked to their destinations, where 


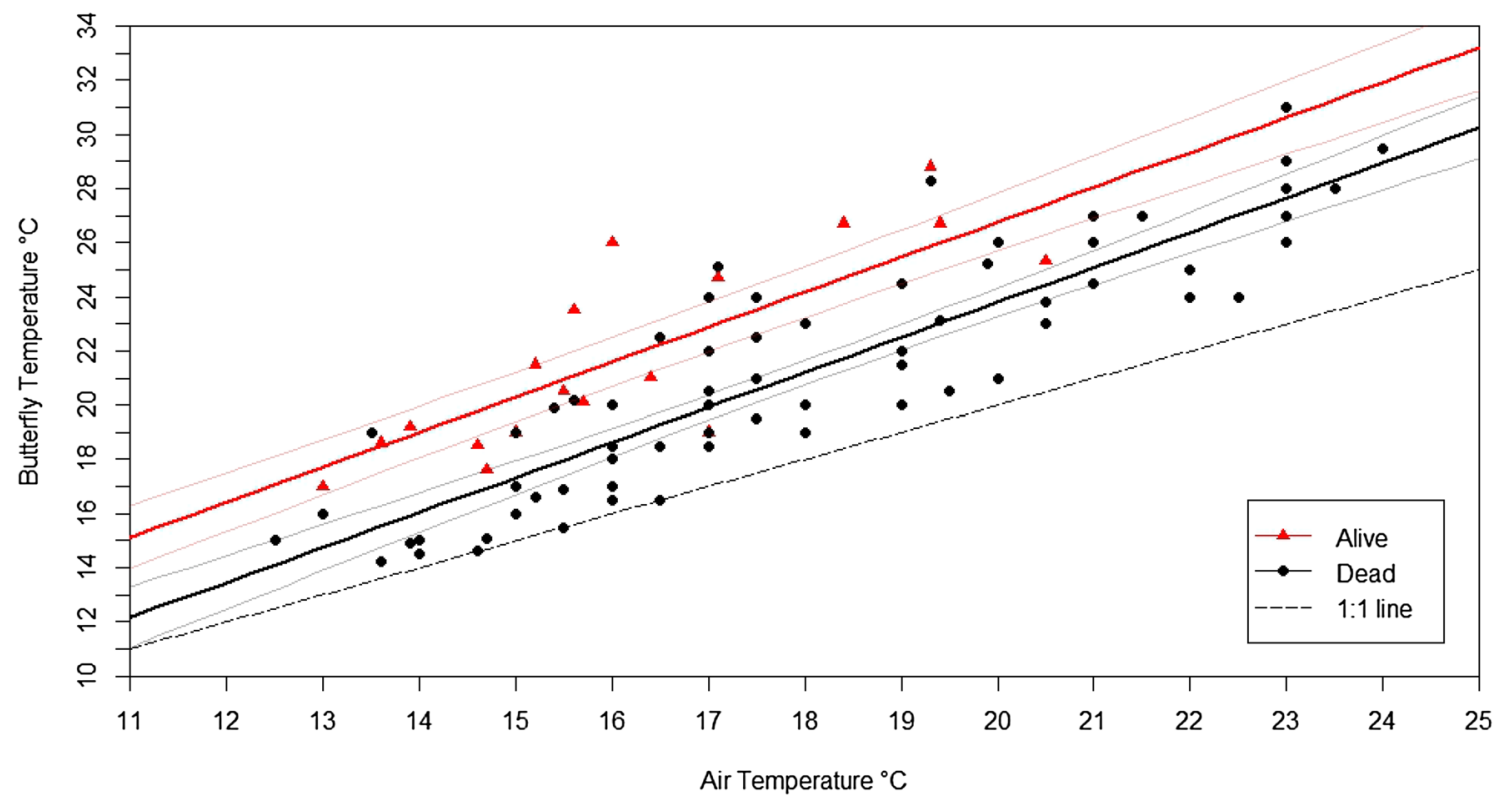

Fig. 5 Thoracic temperature of living (2009) and dead (2009 and 2017) Duke of Burgundy butterflies plotted against air temperature at Totternhoe Quarry Reserve. Separate, parallel linear regressions are

they were found to be nectaring on forget-me-not (Myosotis arvensis) and hawthorn flowers (Crataegus monogyna) respectively.

\section{Discussion}

At higher air temperatures male Duke of Burgundy butterflies increased the number and duration of energetically demanding territorial flights, including those involved with mate interception, which have been suggested to impact reproductive output in other insect species (Shreeve 1984; Tsubaki and Samejima 2016). In contrast, other flights, not associated with maintaining territories or chasing mates, were unaffected by temperature. Male body temperature was closely tied to that of the immediate environment, although living butterflies were significantly warmer than dead butterflies across ambient temperatures. This suggests that despite an ability to raise their temperatures behaviourally, Duke of Burgundy butterflies are dependent on the local microclimate for temperature regulation. Furthermore, the majority of individuals observed had very restricted movement over the observation period and were therefore tied to a single area, which could partly explain their limited ability to buffer their body temperature against changes in the ambient temperature during our observations. However, despite these restrictions, males were found to be slightly more mobile than other studies have previously suggested. plotted for living and dead butterflies respectively $( \pm$ one standard error). A 1:1 regression line where air temperature equals butterfly temperature is also displayed

\section{Multiple males}

Air temperature is only one factor that can affect the number and duration of flight behaviours undertaken by territorial insects, with wind speed (Wickman 1988) and the proximity of other males (Peixoto and Benson 2009) also being reported as being important in other studies. The fact that wind speeds were very similar in this project means that they were not used in analyses, but this does not mean they were unimportant. Indeed, the uniformly low wind speeds recorded where males were present support the suggestion by Turner et al. (2009) that sheltered environments are preferred by adult Duke of Burgundy butterflies, to protect them from unfavourable weather, reducing the effects of wind cooling and promoting flight.

The number of males on a territory resulted in behavioural changes in this study, with higher numbers of males being associated with more territorial flights, but having little effect on non-territorial behaviour. A simple explanation for this pattern is that altering perch location in nonterritorial flights does not require the external stimulus of another butterfly. Conversely, many intercept and all spiral competition territorial flights require other male Duke of Burgundy butterflies to fly through a territory, which will happen much more commonly where more males are present. 


\section{Temperature and flight type}

Warmer environments resulted in a net increase in the number and duration of flight activities performed by the Duke of Burgundy. Globally, many examples exist for activity levels of butterflies and other flying invertebrates being highly constrained by temperature, with species such as the Inornate Ringlet butterfly, Coenonympha inornata (Heinrich 1986) and the Scarce Copper butterfly, Heodes virgaureae (Douwes 1976), rapidly increasing the number of flights they perform as temperatures rise. However, the fact that the net increase in flight activity for the Duke of Burgundy appears to be purely the result of a rise in territorial behaviour, including mate intercept flights, is more notable. Other studies have suggested this behaviour can impact the reproductive success of individuals (Shreeve 1984; Tsubaki and Samejima 2016) with potential consequences for the total population size in an area.

Undertaking more territorial flights can increase mate acquisition rates, but taking off from perches to pursue females or engage in aerial spiral fights on a regular basis is very energetically demanding (Shreeve 1984). Therefore, the trade-off between actively seeking mates and using up energy reserves alters with environmental temperature, as flying becomes relatively less costly when temperatures rise and energy can be replenished more quickly from the environment (Wickman 1985; Ide 2010). Longer periods of powerful active flight, with rapid acceleration, can more easily be sustained at higher temperatures for many flying insects, including the Speckled Wood butterfly, Pararge aegeria (Berwaerts and Van Dyck 2004), and the damselfly Mnais costalis (Samejima and Tsubaki 2010) making the utilisation of such behaviour for mate acquisition more efficient when it is warmer.

A similar trade-off is likely taking place with the Duke of Burgundy, but instead of entirely switching behavioural regimes, rising temperatures result in more territorial behaviour and a decrease in time spent basking. Conversely, small perch alterations are unlikely to be as energetically demanding and so can be undertaken more readily at lower temperatures (Ide 2010), resulting in no significant change in the frequency of non-territorial flights with temperature. More generally, limited options for high activity levels in cool environments also offers an explanation as to why butterfly territoriality is more common in spring-flying species such as the Duke of Burgundy, where temperatures are relatively low, and active patrolling cannot be sustained (Wickman and Wiklund 1983). Building on this study, further research could investigate just how important sustaining territorial activity is to maintaining reproductive populations of this species.

\section{Behavioural thermoregulation and territory occupation}

The data gathered in this study suggest that adult Duke of Burgundy butterflies maintain a higher body temperature than that of their immediate surroundings. However, compared to other species the ability of Duke of Burgundy butterflies to thermoregulate and buffer their body temperature to changes in ambient temperature appears to be relatively poor (Rutowski et al. 1994; Ide 2010; Kleckova and Klecka 2016). Duke of Burgundy butterflies are, therefore, heavily dependent on their environment to provide warm temperatures and enable bouts of energetic territorial behaviour. Measuring air temperature seems to be a suitable way to gauge the temperature being experienced by Duke of Burgundy butterflies, as it is linearly correlated with the thoracic temperature of both dead, passive and living, active individuals. Living butterflies were significantly warmer than their dead counterparts, in part probably due to behavioural thermoregulation (Dreisig 1995). However, we found no evidence for an interaction between the effects of air temperature and living status on the thoracic temperature of the Duke of Burgundy. This suggests that, despite being warmer, the temperature of the living butterflies rises and falls with air temperature in the same way as for dead specimens. This differs from other butterfly species such as the Small Copper, Lycaena phlaeas, and the Woodland Ringlet, Erebia medusa, which can elevate their living thoracic temperature above that of their environment when it is cool, and reduce this difference when it is warmer, often owing to behavioural thermoregulation (Ide 2010; Kleckova and Klecka 2016). For example, the Desert Hackerby, Asterocampa leilia, can use alterations in perch position and body orientation to maintain a roughly constant body temperature as environmental temperature changes (Rutowski et al. 1994). Furthermore, due to living butterflies undertaking energy-intensive active flight, the heat by-product of their metabolism can significantly increase their body temperature. For some species, metabolic heat has been found to raise body temperature by as much as $5{ }^{\circ} \mathrm{C}$ (Ide 2002) and this may account for living Duke of Burgundy butterflies being warmer than dead specimens. Therefore, although Duke of Burgundy butterflies seek out the warmest, most sheltered locations to achieve high body temperatures (Hayes et al. 2018), once there, small scale changes in perch location and body orientation appear to have relatively little effect.

The fact that the majority of males observed remained fixed on their small territories may have further compounded this problem over the observation period, as this reduced butterfly ability to seek out and move to alternate habitats to aid thermoregulation. However, this was not the case for every individual, with $18 \%$ of males flying away from the observation area within the $10 \mathrm{~min}$. Individuals that could 
not be followed were not thought to have dispersed far from the study site, but instead to have undergone displacement within or to the edge of a neighbouring habitat patch (Hovestadt and Nowicki 2008), as was directly observed for three males. However, this limited movement is still more vagrant than previously described for the Duke of Burgundy (Oates 2000). The reason for males leaving their territory is not clear, as most did so without pursuing a conspecific or other flying insect passing through their territory. It has been suggested that nectar supplies are of little importance to the Duke of Burgundy (Oates 2000) but others disagree (Kirtley 1995). Furthermore, the three males that were successfully followed after leaving their territories in this study were all found to be nectaring. This suggests that the pursuit of nectar sources might be an important factor that has to be balanced with time spent occupying a territory. Another possibility is that shifts in territory location could occur due to local changes in temperature, wind speed or direction, as has been previously suggested (Bourn and Warren 1998).

Taken together, the behaviour we observed suggests that the sedentary nature of Duke of Burgundy males may not be quite so extreme as previously thought (Oates 2000). Nevertheless, they are clearly very restricted in their habitat use and the most popular locations at Totternhoe Quarry Reserve are re-used year on year (Hayes et al. 2018), as has been found at other sites for the Duke of Burgundy (Oates 2000). If the Duke of Burgundy is limited in its ability to behaviourally thermoregulate, as this study suggests, this could explain why the distributions of adult males recorded at Totternhoe Quarry are even more restricted than that of their larvae (Hayes et al. 2018); males rely on their environment for shelter and to generate a warm microclimate (Turner et al. 2009).

\section{Conservation in the light of climate change}

To ensure a future for the Duke of Burgundy butterfly in the UK, management directed at the adult life stage, producing warm microclimates that promote energetic flights, including behaviour that may have an impact on the reproductive output of populations (Shreeve 1984; Tsubaki and Samejima 2016) is extremely important. Highly sheltered areas, such as those already occupied by the Duke of Burgundy at Totternhoe Quarry Reserve (Hayes et al. 2018) need to be maintained and replicated where possible (Turner et al. 2009). This is not to say that management for the sensitive larvae of the species is unimportant. However, management aimed solely at the needs of the larvae may not adequately support the Duke of Burgundy throughout its entire lifecycle. Both stages are dependent on shelter but warm southerly slopes that promote adult activity can desiccate Primula spp. food plants, with eggs tending to be laid on other aspects (Hayes et al. 2018). Clearance of scrub to prevent food plants being completely overshadowed is also essential but cannot be too extreme or else areas may become too exposed. Therefore, using moderate rotational scrub clearance to maintain topographically varied sites with sheltered slopes of different aspects, should benefit both life stages (Hayes et al. 2018).

For this spring-flying species (Butterflies Under Threat Team 1986), global warming may significantly reduce the time needed to attain a body temperature sufficient to support active flight (Dennis and Shreeve 1991). Therefore, projected rises in temperature (Intergovernmental Panel on Climate Change 2014) have the potential to benefit the Duke of Burgundy and could help it spread back to the north of the UK, to suitable habitat that has previously been too cool (Thomas et al. 2001). However, the ability of the Duke of Burgundy to track climate change will depend upon the fragmentation and isolation of suitable habitats, the separation of which could impede the species from extending its range (Pollard 1979; Thomas et al. 2001; Warren et al. 2001). Unfortunately, despite some evidence suggesting that in exceptional circumstances the Duke of Burgundy can travel between sites as far as $5 \mathrm{~km}$ apart, the species is generally considered to be a poor disperser (Bourn and Warren 1998). Furthermore, Leon-Cortes et al. (2003), modelling the effects of habitat isolation on the Duke of Burgundy, found that increased dispersal could lead to isolated populations declining more rapidly, as individuals may die before reaching favourable new habitats. Therefore, the ability of the Duke of Burgundy to benefit from regional warming will rely on maintaining habitat quality within a closely connected network of linked sites (Bourn and Warren 1998).

Another potential reason for being optimistic about the future of the Duke of Burgundy in the UK is that species at the edge of their range often occupy a narrower niche and exist in more vulnerable, smaller populations than they do in core areas (Bourn and Thomas 2002). Other heat-dependent butterfly species such as the Large Blue, Phengaris arion, have proven to be particularly hard to conserve in the cooler climates of the UK, but exist across a wider variety of habitats in the warmth of central Europe (Thomas et al. 1998). With increasing regional temperatures, the niche of the Duke of Burgundy may broaden, reducing the specificity of the habitat that can sustain it, and enabling populations in the UK to grow. However, a shift in the realised niche of the species may also necessitate different management regimes at different locations (Anthes et al. 2008), as it does for other butterflies (Bourn and Thomas 2002). Furthermore, as the Duke of Burgundy is dependent on slightly humid calcareous grasslands and its main larval host plant Primula veris appears to be very sensitive to drought (Fartmann 2006), climate change could also threaten populations by making atypical extreme weather patterns more common (Turner et al. 2009). To accommodate the possibility of shifting habitat preferences with changes in climate, conservation 
management needs to be adaptable and assessed regularly. Nature reserves with high aspect and structural variation will be important for providing habitat heterogeneity to buffer against these effects (Fartmann 2006).

\section{Conclusions}

Adult Duke of Burgundy butterflies appear to rely heavily on warm, sheltered habitats to produce suitable temperatures that promote energetically demanding territorial flights, including those involved with mate interception. Studies on other species suggest that undertaking high numbers of these flights may be important for boosting reproductive output. Further research is needed to investigate how far this holds true for populations of the Duke of Burgundy and whether this has a net beneficial impact on population sizes, but nevertheless our findings reinforce the need to maintain suitable habitats specifically for the adult life stage of this species, in addition to areas being conserved to meet the needs of the larvae. The importance of high temperatures for the species suggests that it may be able to benefit from projected global warming. However, the ability of the Duke of Burgundy to track climate change north in the UK will depend on habitat availability and fragmentation. Work must be carried out to link up sites and produce adaptable management regimes with the butterflies' microclimate in mind. Furthermore, with observations indicating that males may be slightly more mobile at the local scale than other studies suggest, more research is needed to better understand the complex requirements of the Duke of Burgundy's adult life stage.

\begin{abstract}
Acknowledgements We would like to thank all of the BCN Wildlife Trust staff and volunteers, as well as members of the Insect Ecology Research Group at the Department of Zoology, Cambridge, for their help and support during this project. All work was carried out with the full consent of the BCN Wildlife Trust and Natural England. We would also like to thank the Isaac Newton Trust and Christ's College who jointly funded MPH's Newton College Masters Studentship during this project.
\end{abstract}

Funding The funding for this project comes from MPH's Newton College Masters Studentship, funded by the Isaac Newton Trust and Christ's College to support 1 year of graduate research. This fund does not have a Grant Number.

\section{Compliance with ethical standards}

Conflict of interest The authors declare that they have no conflict of interest.

Research involving human and animal participants No butterflies were harmed during the course of this project. All work was carried out with the full consent of the BCN Wildlife Trust on one of their reserves and they work closely with Natural England to ensure the best monitoring of species on their sites. Natural England also provided the BCN Wildlife Trust with written consent to undertake adult butterfly surveys of scarce species and Duke of Burgundy larval damage surveys specifically. Please see 'Consent of Natural England' form.

Informed consent No data were collected from human participants during this project.

Open Access This article is distributed under the terms of the Creative Commons Attribution 4.0 International License (http://creativeco mmons.org/licenses/by/4.0/), which permits unrestricted use, distribution, and reproduction in any medium, provided you give appropriate credit to the original author(s) and the source, provide a link to the Creative Commons license, and indicate if changes were made.

\section{References}

Anthes N, Fartmann T, Hermann G (2008) The Duke of Burgundy butterfly and its dukedom: larval niche variation in Hamearis lucina across Central Europe. J Insect Conserv 12(1):3-14

Bennett VJ, Betts MG, Smith WP (2014) Influence of thermal conditions on habitat use by a rare spring-emerging butterfly Euphydryas editha taylori. J Appl Entomol 138:623-634

Berwaerts K, Van Dyck H (2004) Take-off performance under optimal and suboptimal thermal conditions in the butterfly Pararge aegeria. Oecologia 141(3):536-545

Bourn NAD, Thomas JA (2002) The challenge of conserving grassland insects at the margins of their range in Europe. Biol Conserv 104:285-292

Bourn NAD, Warren MS (1998) Species action plan: duke of Burgundy Hamearis lucina. Butterfly Conservation, Wareham

Butterflies Under Threat Team (1986) The management of chalk grassland for butterflies. Focus on nature conservation No 17. Nature Conservancy Council, Peterborough

Butterfly Conservation (2019) Duke of Burgundy. https://butterflyconservation.org/butterflies/duke-of-burgundy. Accessed 13 May 2019

Dennis RLH, Shreeve T (1991) Climatic change and the British butterfly fauna: opportunities and constraints. Biol Conserv 55:1-16

Douwes P (1976) Activity in Heodes virgaureae (Lep., Lycaenidae) in relation to air temperature, solar radiation, and time of day. Oecologia 22(3):287-298

Dreisig H (1995) Thermoregulation and flight activity in territorial male graylings, Hipparchia semele (Satyridae), and large skippers, Ochlodes venata (Hesperiidae). Oecologia 101(2):169-176

Ellis S, Wainwright D, Berney F, Bulman C, Bourn N (2011) Landscape-scale conservation in practice: lessons from northern England, UK. J Insect Conserv 15(1):69-81

Emmet AM, Heath J (1989) The moths and butterflies of Great Britain and Ireland, Vol. 7, Part 1, Hesperiidae-Nymphalidae. The Butterflies. Harley Books, Colchester

Fartmann T (2006) Oviposition preferences, adjacency of old woodland and isolation explain the distribution of the Duke of Burgundy butterfly (Hamearis lucina) in calcareous grasslands in central Germany. Ann Zool Fenn 43:335-347

Fox R, Brereton TM, Asher J, August TA, Botham MS, Bourn NAD, Cruickshanks KL, Bulman CR, Ellis S, Harrower CA, Middlebrook I, Noble DG, Powney GD, Randle Z, Warren MS, Roy DB (2015) The State of the UK's Butterflies 2015. Butterfly Conservation and the Centre for Ecology \& Hydrology, Wareham

Hayes MP, Hitchcock GE, Knock RI, Lucas CBH, Chaney PK, Rhodes MW, Turner EC (2018) Determining the long-term habitat preferences of the Duke of Burgundy butterfly, Hamearis 
lucina, on a chalk grassland reserve in the UK. J Insect Conserv 22(2):329-343

Heiberger RM, Holland B (2004) Springer Texts in Statistics. In: Statistical analysis and data display: an intermediate course with examples in S-plus, R, and SAS. Springer, New York

Heinrich B (1986) Thermoregulation and flight activity Satyrinae, Coenonympha inornata (Lepidoptera: Satyridae). Ecology 67(3):593-597

Hovestadt T, Nowicki P (2008) Investigating movement within irregularly shaped patches: analysis of mark-release-recapture data using randomization procedures. Isr J Ecol Evol 54(1):137-154

Huey RB, Kingsolver JG (1989) Evolution of thermal sensitivity of ectotherm performance. Tree 4(5):131-135

Ide JY (2002) Seasonal changes in the territorial behaviour of the satyrine butterfly Lethe diana are mediated by temperature. J Ethol 20(1):71-78

Ide JY (2010) Weather factors affecting the male mate-locating tactics of the small copper butterfly (Lepidoptera: Lycaenidae). Eur J Entomol 107(3):369-376

Intergovernmental Panel on Climate Change (2014) Climate Change 2014: Synthesis Report. Contribution of Working Groups I, II and III to the Fifth Assessment Report of the Intergovernmental Panel on Climate Change. Intergovernmental Panel on Climate Change, Geneva, Switzerland

Kirtley S (1995) The current status and ecology of the Duke of Burgundy butterfly (Hamearis lucina L.) in South Cumbria and North Lancashire. Report to English Nature

Kleckova I, Klecka J (2016) Facing the heat: thermoregulation and behaviour of lowland species of a cold-dwelling butterfly Genus, Erebia. PLoS ONE 11(3):e0150393

Larsson FK, Kustvall V (1990) Temperature reverses size-dependent male mating success of a cerambycid beetle. Funct Ecol 4(1):85-90

Larsson FK, Tengo J (1989) The effects of temperature and body size on the mating pattern of a gregariously nesting bee, Colletes cunicularius (Hymenoptera: Colletidae). Ecol Entomol 14(3):279-286

Leon-Cortes JL, Lennon JJ, Thomas CD (2003) Ecological dynamics of extinct species in empty habitat networks. 1. The role of habitat pattern and quantity, stochasticity and dispersal. Oikos 102(3):449-464

Merckx T, Van Dyck H (2005) Mate location behaviour of the butterfly Pararge aegeria in woodland and fragmented landscapes. Anim Behav 70(2):411-416

Met Office (2017) Beaufort wind force scale. http://www.metoffice.gov. uk/guide/weather/marine/beaufort-scale. Accessed 26 Aug 2017

Oates M (2000) The Duke of Burgundy-conserving the intractable. Br Wildl 11:250-257

Parmesan C, Ryrholm N, Stefanescu C, Hill JK, Thomas CD, Descimon H, Huntley B, Kaila L, Kullberg J, Tammaru T, Tennent WJ, Thomas JA, Warren M (1999) Poleward shifts in geographical ranges of butterfly species associated with regional warming. Nature 399:579-583

Peixoto PEC, Benson WW (2009) Seasonal effects of density on territory occupation by males of the satyrine butterfly Paryphthimoides phronius (Butler 1867). J Ethol 27(3):489-496

Pollard E (1979) Population ecology and change in range of the white admiral butterfly Ladoga camilla L. England. Ecol Entomol 4(1):61-74

Rutowski RL, Demlong MJ, Leffingwell T (1994) Behavioural thermoregulation at mate encounter sites by male butterflies (Asterocampa leilia, Nymphalidae). Anim Behav 48(4):833-841
Samejima Y, Tsubaki Y (2010) Body temperature and body size affect flight performance in a damselfly. Behav Ecol Sociobiol 64(4):685-692

Scott J (1974) Mate-locating behavior of butterflies. Am Midl Nat 91(1):103-117

Shreeve TG (1984) Habitat selection, mate location, and microclimatic constraints on the activity of the speckled wood butterfly Pararge aegeria. Oikos 42(3):371-377

Sparks TH, Porter K, Greatorex-Davies JN, Hall ML, Marrs RH (1994) The choice of oviposition sites in woodland by the Duke of Burgundy butterfly Hamearis lucina in England. Biol Conserv 70:257-264

Stevenson RD (1985) Body size and limits to the daily range of body temperature in terrestrial ectotherms. Am Nat 125(1):102-117

Thomas JA, Simcox DJ, Wardlaw JC, Elmes GW, Hochberg ME, Clarke RT (1998) Effects of latitude, altitude and climate on the habitat and conservation of the endangered butterfly Maculinea arion and its Myrmica ant hosts. J Insect Conserv 2:39-46

Thomas CD, Bodsworth EJ, Wilson RJ, Simmons AD, Davies ZG, Musche M, Conradt L (2001) Ecological and evolutionary processes at expanding range margins. Nature 411:577-581

BCN Wildlife Trust, Totternhoe (2017). http://www.wildlifeben.org/ reserves/totternhoe. Accessed 29 Aug 2017

Tsubaki Y, Samejima Y (2016) Hot males live fast and die young: habitat segregation, reproductive output, and lifespan of sympatric Mnais damselflies. Behav Ecol Sociobiol 70(5):725-732

Turner EC, Granroth HMV, Johnson HR, Lucas CBH, Thompson AM, Froy H, German RN, Holdgate R (2009) Habitat preference and dispersal of the Duke of Burgundy butterfly (Hamearis lucina) on an abandoned chalk quarry in Bedfordshire, UK. J Insect Conserv 13(5):475-486

Van Dyck H, Matthysen E (1998) Thermoregulatory differences between phenotypes in the speckled wood butterfly: hot perchers and cold patrollers? Oecologia 114:326-334

Warren MS, Hill JK, Thomas JA, Asher J, Fox R, Huntley B, Roy DB, Telfer MG, Jeffcoate S, Harding P, Jeffcoate G, Willis SG, Greatorex-Davies JN, Moss D, Thomas CD (2001) Rapid responses of British butterflies to opposing forces of climate and habitat change. Nature 414:65-69

Wasserthal LT (1975) The role of butterfly wings in regulation of body temperature. J Insect Physiol 21(12):1921-1930

Wickman PO (1985) The influence of temperature on the territorial and mate locating behaviour of the small heath butterfly, Coenonympha pamphilus (L.) (Lepidoptera: Satyridae). Behav Ecol Sociobiol 16(3):233-238

Wickman PO (1988) Dynamics of mate-searching behavior in a hilltopping butterfly, Lasiommata megera $(\mathrm{L})$ : the effects of weather and male density. Zool J Linn Soc 93:357-377

Wickman PO, Wiklund C (1983) Territorial defence and its seasonal decline in the speckled wood butterfly (Pararge aegeria). Anim Behav 31(4):1206-1216

Willmer P (1991) Thermal biology and mate acquisition in ectotherms. Tree 6(12):396-399

Publisher's Note Springer Nature remains neutral with regard to jurisdictional claims in published maps and institutional affiliations. 